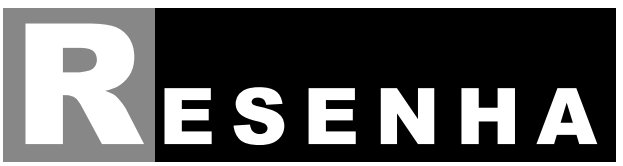




\section{MASCARELLO, Magda Luiza. 0 barracão e a rua: experiências e práticas políticas de catadores de materiais recicláveis em Curitiba (PR). Rio de Janeiro: Gramma: Terceiro Nome, 2018.}

\section{Martina Ahlert}

Brasil. Universidade Federal do Maranhão. Professora do Departamento de Sociologia e Antropologia, e do Programa de Pós-Graduação em Ciências Sociais da Universidade Federal do Maranhão. Doutora em Antropologia Social pela Universidade de Brasilia. ID ORCID: http://orcid.org/0000-0001-5735-5441. E-mail:ahlertmartina@gmail.com.

O livro de Magda Mascarello discorre sobre o cotidiano de mulheres e homens, moradores de Curitiba, que compõem o Mutirão, um coletivo de catadores de materiais recicláveis. Enquanto etnografia, a obra permite ao leitor caminhar pelas miudezas das atividades diárias desses trabalhadores - que sentem texturas, classificam objetos, constroem espaços de trabalho -, ao mesmo tempo que os conecta, como parte de uma rede, aos engajamentos religiosos de cunho social e às políticas públicas municipais e nacionais.

O barracão e a rua dialoga com certa antropologia urbana e com determinada antropologia da política feita no Brasil. Como lembra Sandra Stoll (2008), orientadora da dissertação da qual o livro se origina, é em Curitiba, que já recebeu as alcunhas de "cidade ecológica", "moderna" e "europeia", que se desenham os itinerários dos catadores. A partir da ação da catação que a cidade é vivida, pois por ela se interpretam prédios, lixeiras e depósitos. A capital paranaense que se apresenta ao leitor é formada pelo Bairro Novo, uma área de loteamentos populares e ocupações informais que conversa com seu entorno por intermédio da circulação de pessoas como Joana, Francisco e Catarina. 
Se os caminhos são tecidos na dinâmica da cidade, os rendimentos teórico-metodológicos do livro crescem no diálogo com a antropologia de Claudia Fonseca (2006), que coloca em primeiro plano os desafios de pensar a alteridade em relação a classe social e pobreza. É a partir das provocações da autora em relação à forma como a antropologia percebe essas categorias que Mascarello pensa seu posicionamento analítico, uma vez que seu envolvimento com o Mutirão antecedeu a pesquisa da dissertação e a colocou em diferentes funções de trabalho no local. Para que a etnografia pudesse ser feita, toda a proximidade com esse universo teve que ser repensada, e a pesquisadora deixou de ser considerada pelos catadores como uma pessoa do próprio grupo para se tornar alguém que "já não sabe fazer projetos e parece não conhecer mais o Mutirão" (MASCARELLO, 2018, p. 28).

Outro eixo de diálogo ainda constitui, de forma ampla, as abordagens de Mascarello: um olhar que se desdobra à antropologia da política interessada na multiplicidade desse conceito, algo que nos remete aos trabalhos do Núcleo de Antropologia da Política (NuAP). Cabe destacar o suporte encontrado nas abordagens de Antonádia Borges (2003) e o uso que Mascarello faz da ideia de "lugares-evento", por sua vez proveniente do trabalho de Daniel (1996). É a partir dos "lugares-evento" - espaços que são também ações - que se organizam os capítulos do livro: "O Mutirão", "O terreno", "O barracão" e os "Catadores".

O primeiro capítulo, intitulado "O Mutirão", considera esse coletivo de catadores como um compósito e traz ao leitor narrativas múltiplas - e, algumas vezes, contraditórias - sobre sua constituição. Quando os interlocutores de Magda Mascarello falavam sobre o Mutirão, era de forma articulada com suas próprias histórias de vida, a formação do Bairro Novo e a atuação da Igreja Católica, orientada para a Teologia da Libertação e o "trabalho com os pobres". A estratégia de evidenciar as contradições nas narrativas sobre o coletivo é uma forma de apostar não em uma história oficial e genérica do Mutirão, mas nos eventos e personagens que, em relação uns com os outros, são mencionados nas falas ouvidas em campo.

Um ponto comum das narrativas era olugar de duas figuras centrais na constituição do Mutirão, pois são consideradas os "primeiros": a irmã católica Teresa, 
que mobilizou o início do projeto e nele atuou durante alguns anos; e Francisco, um catador (cujo enterro é eixo articular de toda a obra). Estes, em conjunto com voluntários afeitos à militância religiosa, foram responsáveis pela iniciativa que buscava melhores condições de trabalho para os catadores, disponibilizando alimentação, carrinhos para a coleta dos materiais recicláveis e um espaço para seu armazenamento. Teresa e Francisco, como “primeiros", representavam uma “conjugação da fé que compreende a miséria humana e a imagem dessa pobreza corporificada nas condições de vida” (MASCARELLO, 2018, p. 70-71).

O tempo dos "primeiros" é também um lugar, o terreno - que nomeia o segundo capítulo. Nesse espaço físico contíguo a uma casa de apoio articulada por irmã Teresa, os catadores antes individualizados se tornam grupo organizado, se profissionalizam e passam a comercializar, coletivamente, o fruto diário da catação. No terreno, o trabalho com o lixo se torna sinônimo de dignidade e honestidade. Posteriormente, é onde o projeto se transforma, acompanhando alterações da configuração organizacional da Igreja Católica no Bairro Novo - mudanças que levam ao afastamento da religiosa e, consequentemente, trazem um conjunto de dificuldades financeiras aos catadores.

No terreno, o Mutirão se organiza em "cantos" - unidades de produção onde cada catador trabalha com seus familiares na seleção do material recolhido por si nas ruas de Curitiba. Constituídos eles mesmos de material reciclável, formam uma paisagem efêmera e continuamente recomposta de objetos classificados segundo utilidades, possibilidades de troca, afetos e expectativas. Nesse espaço-tempo os catadores passam a se definir como "antigos" (os que estavam desde o começo da proposta e seus familiares) e "novos" (aqueles que chegaram posteriormente). Ali a imagem do catador se constitui de forma dupla: tanto como vítima quanto como herói, em um mundo onde imperam as dificuldades provenientes da desigualdade social.

Os problemas financeiros enfrentados pelo Mutirão e a nova configuração da relação com a Igreja Católica aproximam os catadores de novos atores (como as cooperativas, fóruns e a prefeitura). Nesse momento, os trabalhadores se questionam sobre a "essência" que os constitui e sobre os caminhos "tentadores" dos engajamentos políticos. O cenário de consolidação da Política 
Nacional de Resíduos Sólidos e o emaranhado dessas relações constituem o barracão (terceiro capítulo) - espaço municipal para onde os catadores se deslocam enquanto aguardam a construção de seu próprio local de trabalho pela prefeitura. No barracão surgem botas, luvas e uniformes, reuniões, técnicos profissionais, visitantes e interessados em conhecer um "movimento organizado". Surgem ainda diversos trabalhadores que não catam resíduos sólidos nas ruas, mas separam o material proveniente dos caminhões de coleta seletiva (chamados de "os do Separe", em oposição aos "carrinheiros").

A nova organização de trabalho e a presença de atores diversos nas relações do Mutirão levam Mascarello a definir o barracão como "lócus de parcerias" e a buscar compreender, pela circulação dos catadores em diferentes cenários de atuação política, as relações concretas entre diferentes organizações. O engajamento no cenário político das parcerias leva os trabalhadores a ocuparem seu tempo participando de reuniões, recebendo visitantes e promovendo contatos - o que aumenta sua jornada de trabalho e, eventualmente, leva seus corpos à exaustão. A instabilidade dos relacionamentos nesse cenário coloca o Mutirão em um novo momento de crise - ocasionado especialmente pela má qualidade e baixa quantidade do material proveniente da coleta seletiva - e leva alguns dos catadores de volta ao terreno. Evidencia-se a contínua tensão entre o "ideal de autarquia [valorizado sobremodo pelos catadores] e o imperativo da relação" (MASCARELLO, 2018, p. 167).

Em todo esse processo espaço-temporal, altera-se a definição de catador, como nos permite entender o quarto capítulo. No início do projeto Mutirão, "antigos" (aqueles que estavam desde o começo e seus parentes) e "novos" (aqueles que ingressaram posteriormente) eram considerados catadores, pois todos faziam a coleta nas ruas. No barracão, no entanto, a classificação entre "antigos" e "novos" se altera e se sobrepõe àquela entre os "carrinheiros" e "os do Separe". "Os do Separe" passaram a ser chamados de "novos". Sua rotina, caracterizada por menor margem de manobra em relação ao tempo (pois dependiam dos caminhões da prefeitura), proporcionava renda inferior à dos "carrinheiros". Estes, por utilizarem carrinhos para a coleta nas ruas e terem vindo do terreno, passaram a ser "os antigos". A atuação política era sua prerrogativa, e eles eram 
vistos como aqueles que tinham a oratória e a jocosidade necessárias no cenário das "parcerias". Eram ainda os "antigos" que buscavam "benefícios" para todo o grupo e se pautavam pelo "justo" e pelo "honesto". Por possuírem maior liberdade na organização do seu próprio tempo, diziam "não ter patrão" e, desta forma, ostentavam o valor da autonomia, considerando-se os "verdadeiros catadores".

A etnografia de Magda Mascarello pode ser abordada por caminhos diversos: ela discute cidade, política, objetos, circulação/mobilidade e religião. Dela se desdobram considerações sobre dois processos dinâmicos que falam de movimentos: (i) entre individuação e coletivização - quando a autora nos apresenta as dificuldades na constituição de engajamentos e grupos, a distância entre os desejos dos trabalhadores e os aspectos práticos necessários para constituir um "grupo organizado" (como documentos e licenças, por exemplo); e (ii) entre o valor da autonomia e a necessidade das parcerias - quando nos mostra as escolhas políticas de pessoas e grupos para não se sentirem presos, diluindo parcerias ao mesmo tempo que reconhecem sua necessidade.

Além desses pontos, aspectos do trabalho têm diálogo com diversas etnografias contemporâneas feitas por outros pesquisadores jovens no Brasil. No reconhecimento da "toxicidade" da relação com a política institucional e dos caminhos que afastam os trabalhadores quando se tornam militantes, é possível dialogar com a etnografia sobre os moradores de rua de Porto Alegre feita por Lemões da Silva (2017); no uso da jocosidade e do humor como elemento significativo de participação política, que tem como eixo "tirar do sério" os opositores, remetemo-nos ao trabalho sobre a pirraça no Quilombo da Malhada, na Bahia, como nos propõe Suzane Alencar Vieira (2015); nas regras que não são um corpo fixo, mas são ideias que precisam ser cuidadosamente colocadas em circulação (ou mesmo silenciadas), encontramos a etnografia de Karina Biondi (2017) sobre o crime em São Paulo. Todas essas pesquisas baseadas na convivência com as pessoas - às quais se soma o trabalho de Magda Mascarello - nos falam deste momento produtivo dos estudos antropológicos sobre a multiplicidade das experiências políticas no Brasil contemporâneo. 


\section{REFERÊNCIAS BIBLIOGRÁFICAS}

1. BIONDI, Karina. A gestão das ideias em uma etnografia no movimento. In: COMERFORD, John; BEZERRA, Marcos Otávio; PALMEIRA, Moacir (org.). Questões e dimensões da política: anais do Encontro dos 20 anos do Núcleo de Antropologia da Política (NuAP). Rio de Janeiro: Papéis Selvagens, 2017. p. 219-228.

2. BORGES, Antonádia. Tempo de Brasília: etnografando lugares-evento da política. Rio de Janeiro: Relume Dumará, 2003.

3. DANIEL, E. Valentine. Charred lullabies: chapters in an anthropography of violence. Princeton: Princeton University Press, 1996.

4. FONSECA, Claudia. Classe a recusa etnográfica. In: FONSECA, Claudia; BRITES, Jurema (org.). Etnografias da participação. Santa Cruz do Sul: Edunisc, 2006. p. 13-34.

5. MASCARELLO, Magda Luiza. O barracão e a rua: experiências e práticas políticas de catadores de materiais recicláveis em Curitiba (PR). Rio de Janeiro: Gramma: Terceiro Nome, 2018.

6. SILVA, Tiago Lemões da. De vidas infames à máquina de guerra: etnografia de uma luta por direitos. 2017. Tese (Doutorado em Antropologia Social) Universidade Federal do Rio Grande do Sul, Porto Alegre, 2017.

7. STOLL, Sandra. Prefácio. In: MASCARELLO, Magda Luiza. O barracão e a rua: experiências e práticas políticas de catadores de materiais recicláveis em Curitiba (PR). Rio de Janeiro: Gramma: Terceiro Nome, 2018. p. 11-13.

8. VIEIRA, Suzane Alencar. Resistência e Pirraça na Malhada: cosmopolíticas quilombolas no Alto Sertão de Caetité. 2015. Tese (Doutorado em Antropologia Social) - Museu Nacional, Universidade Federal do Rio de Janeiro, Rio de Janeiro, 2015. 